\title{
Exposure to Aerosols Particles on an Urban Road
}

\author{
Adam Piotrowicz', Bernard Polednik ${ }^{1 *}$ \\ 1 Lublin University of Technology, Faculty of Environmental Engineering, Lublin, Poland \\ * Corresponding author's e-mail: b.polednik@pollub.pl
}

\begin{abstract}
Traffic-related emissions, apart from emissions from fuel combustion for heating purposes, significantly deteriorate air quality in cities. The above mainly concerns areas located close to busy traffic routes. According to epidemiological studies, traffic-related emissions have an adverse health effect. This specifically affects commuters (drivers and car passengers) as well as pedestrians. The aim of this study was to determine the variations of particle number and mass concentrations along a busy road in Lublin, Poland and their impact on the particle exposure for commuters and pedestrians. On-route and fixed-site measurements were performed in the summer (June) with a focus on peak and off-peak traffic hours and road sections with low and high traffic intensity. During peak hours, the average number concentration of ultrafine particles $\left(\mathrm{PN}_{0.1}\right)$ in the road section near 4-way traffic intersections (TIs) was about 2 times higher than during off-peak hours. The average mass concentration of fine particles $\left(\mathrm{PM}_{2.5}\right) \mathrm{was}$ also approximately twice as high than in off-peak hours. Similar relations were found for other measured aerosol particles as well as with respect to particle exposure. The obtained results indicate the need for further extended research on traffic-related emissions and exposure and the ways of limiting them.
\end{abstract}

Keywords: ambient air quality, vehicle emission, particulat matter, health effects

\section{INTRODUCTION}

Air quality in cities is largely dependent on ambient air particle concentrations. Such aerosol particles originate from natural sources such as plants or buildings [Suchorab et al. 2017]. Anthropological particle sources are mainly from combustion processes e.g. residential coal-burning and transportation [Polednik 2013]. They may contain hazardous substances, among other things, polycyclic aromatic hydrocarbons such as benzo(a)pyrene, heavy metals as well as dioxins and furans [Klejnowski et al.2010]. Currently only mass concentrations of $\mathrm{PM}_{10}$ and $\mathrm{PM}_{2.5}$ particles (with an aerodynamic diameter smaller than 10 $\mu \mathrm{m}$ and $2.5 \mu \mathrm{m}$, respectively) are regularly monitored in urban agglomerations. However, greater attention is being drawn to concentrations of ultrafine particles (UFP) with a diameter of less than $100 \mathrm{~nm}$ which were found to have potentially the highest adverse health effects [Kumar et al. 2014].

Epidemiological studies have found an association between concentrations of UFP and health hazards such as respiratory and cardiovascular diseases and processes leading to carcinogenesis [Valavanidis et al. 2008]. Therefore, the share of UFP in the total particle concentration should be considered while monitoring urban air quality. This is due to the fact that UFPs are a material component of $\mathrm{PM}_{2.5}$ for which legal standards are established by the World Health Organization [WHO 2006]. According to the European Environment Agency, in 2013 about 87\% of urban population in the European Union was exposed to $\mathrm{PM}_{2.5}$ concentrations which exceeded the daily limit imposed by the WHO for outdoor air pollution. In 2012, 403000 premature deaths in the EU were linked to $\mathrm{PM}_{2.5}$ exposure [EEA 2017]. Transportation is considered to be responsible for such increased exposure, especially since the number of cars in urban areas is constantly increasing. In turn, due to heavier traffic, travelling time has increased over the years which results in a growing need for a more accurate exposure assessment. Accurate estimates are, however, difficult as exposure depends on 
many factors such as traffic intensity, number of trucks and passenger cars or type of fuel as well as the topography and the built-up area around the individual routes. It is important to stress that even for a given route exposure-related factors such as traffic characteristics and weather conditions are subject to frequent changes. Traffic intersections (TIs) are considered to be pollution hotspots [Goel and Kumar 2015]. Data for exposure assessments can be provided through mobile and fixed-site measurements. The former produce input concerning commuters' (drivers' and car passengers') exposure to particles, while the latter may constitute a basis for evaluating particle exposure of pedestrians. One advantage of mobile measurements is that they allow for obtaining significant volumes of data for vast areas in a relatively short period of time.

This paper shows changes of particle number and mass concentrations, including UFP concentrations on one of the busiest roads in Lublin, Poland in peak and off-peak traffic times. Their impact on the particle exposure for commuters and pedestrians was also assessed.

\section{METHODS}

The research was conducted in Lublin, the largest city in eastern Poland with a population of 340,230 (June 2017). Mobile measurements were performed along a $2.1 \mathrm{~km}$ long route forming part of one of the busiest streets in the city (Figure 1). The route included three 4-way TIs and three 3-way TIs. Fixed-site measurements were performed in 12 evenly distributed points on the sidewalk along the route. Three of them were located in the vicinity of 4-way TIs and three in the vicinity of 3-way TIs.

Measurements were carried out with the use of the Mobile Air Pollution Analytic Laboratory (MAPAL) installed in a Renault Kangoo (2008 registration; $1461 \mathrm{cc}$ ). Test runs were made in both directions. Stops were made at 12 measurement points and 5-minute fixed-site measurements were performed with MAPAL parked on the sidewalk, at the curbstone. Attempts were made to stop at each designated point, however, it was not always possible due to traffic conditions. Measurements were performed within 24 hours on 21/22 June 2017. Six runs a day were made which included morning and afternoon peak hours, off-peak hours in the evening and at night. The duration of the runs varied depending on the period of the day and the related traffic intensity. On average, one full run took approximately 95 minutes.

The adopted measurement criteria allowed MAPAL to perform measurements as part of one run at comparatively similar traffic conditions. This paper presents the results of morning peak hour and evening off-peak hour measurements.

MAPAL was equipped, among other things, with the Grimm Aerosol Spectrometer 1.109 with Nano Sizer 1.321 (Grimm Aerosol Germany), ultrafine particle counter P-Trak model 8525 (TSI Inc. USA), optical spectrometer OPS 3330 (TSI Inc. USA) and aerosol monitor DustTrak DRX model 8533 (TSI Inc. USA). Air samples were supplied to MAPAL through tubes with endpoints located in the middle of the vehicle, on the left side, at the height of approximately $1.7 \mathrm{~m}$. The logging interval for the instruments was 6 seconds. All instruments were calibrated by their manufacturer at the beginning of the measurements. Timestamps were matched at the beginning of the experiment. Global Positioning System (GPS; Garmin Nuvi 2460LMT) with an HD $1080 \mathrm{P}$ wide angle $170^{\circ}$ camera located on the dashboard of the car was used to monitor the exact location of MAPAL and to collect traffic flow data. Methodology presented in Joodatnia et al. [2013] was applied to determine the respiratory deposition rate $(D R)$ of car drivers and passengers (commuters) and of pedestrians. In this study, the average deposition rate of the inhaled particles in the respiratory tract was estimated by using the following equation (1):

$$
D R=V_{T} \cdot f \cdot D F \cdot P C
$$

where: $V_{T}$ is the tidal volume,

$f$ is the breathing frequency,

$D F$ is the deposition fraction and

$P C$ is the particle number or mass concentration.

The tidal volume and breathing rate were assumed respectively as $800 \mathrm{~cm}^{3}$ per breath and as 18 per minute for a male adult commuter and as 21 per minute for a male adult pedestrian. $D F$ values of 0.25 and 0.65 , respectively were assumed for the purpose of estimating the deposition rate of the number of inhaled ultrafine and large particles [Sturm 2016, Joodatnia et al. 2013]. For the mass of the inhaled particles, $D F$ values were adopted from Kumar and Goel [2016] and for $\mathrm{PM}_{2.5}$ and $\mathrm{PM}_{10}$ amounted to respectively 0.23 and 0.88 (commuters) and 0.14 and 0.88 (pedestrians). 


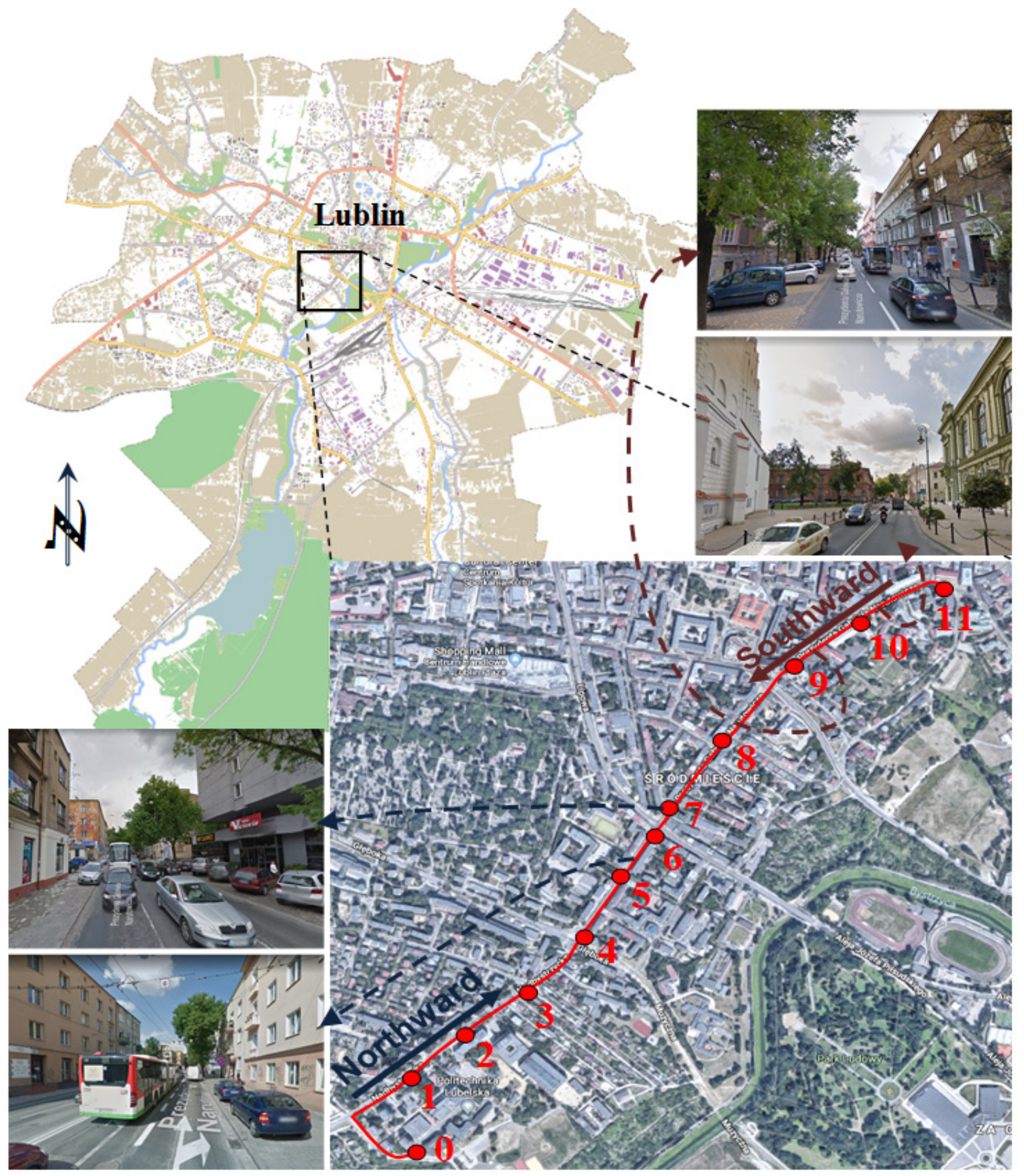

Figure 1. Map of Lublin (Google Earth) with the location of the route for mobile monitoring and the fixedsite measurement points on the sidewalk along the route and pictures of the road (off-peak traffic time)

All calculations and data analyses were performed with the use of software package Statistica 13.1 (StatSoft).

\section{RESULTS AND DISCUSSION}

The measurements allowed for tracking number and mass concentration changes of particles with a wide range of sizes both along the route and in the given measurement points at different times of the day. It needs to be emphasized that the results differed depending on the instrument used [Połednik et al. 2018]. For the sake of consistency, only results obtained in peak (8:00) and off-peak (20:00) hours with the use of Grimm and P-track instruments are further discussed in this paper.

Figure 2 presents variations of ultrafine and submicron particle number concentrations $\left(\mathrm{PN}_{0.1}\right.$ and $\left.\mathrm{PN}_{1}\right)$ and mass concentrations of fine 
and coarse particles $\left(\mathrm{PM}_{2.5}, \mathrm{PM}_{10}\right)$ in peak and off-peak hours.

The measured particle concentrations changed considerably along the monitored route. The greatest changes were observed during peak traffic hours and near 4-way TIs (near measurement points 4, 7 and 9). The highest concentrations of $\mathrm{PN}_{01}, \mathrm{PN}_{1}, \mathrm{PM}_{2.5}$ and $\mathrm{PM}_{10}$ in the peak time amounted to $53.6 \times 10^{3} \mathrm{pt} / \mathrm{cm}^{3} 266.8 \times 10^{3} \mathrm{pt} / \mathrm{cm}^{3}$. $53.0 \mu \mathrm{g} / \mathrm{m}^{3}$ and $72.1 \mu \mathrm{g} / \mathrm{m}^{3}$, respectively. The maximum concentrations obtained for these particles in the off-peak time were about 2-3 times lower and equaled $27.2 \times 10^{3} \mathrm{pt} / \mathrm{cm}^{3}, 94.3 \times 10^{3} \mathrm{pt} /$ $\mathrm{cm}^{3} 26.3 \mu \mathrm{g} / \mathrm{m}^{3}$ and $42.5 \mu \mathrm{g} / \mathrm{m}^{3}$, respectively. During peak hours, the average $\mathrm{PN}_{0.1}$ concentration in the road section near 4-way TIs amounted to 17.2 $\pm 13 \times 10^{3} \mathrm{pt} / \mathrm{cm}^{3}$ (mean \pm standard deviation) and was about 2 times higher than during off-peak hours. The average $\mathrm{PM}_{2.5}$ concentration amounted to $21.8 \pm 9.4 \mu \mathrm{g} / \mathrm{m}^{3}$ and was also approximately twice as high than in off-peak hours. Similar relations were seen in peak and off-peak hours in the fixed-site measurement points. They are clearly visible in the differences of the average particle concentration values presented in Figure 3.

The presented data indicates that the values of the measured particle concentrations are mainly affected by the traffic intensity and the related varied particle emissions. In general, according to numerous previous studies, ultrafine and fine particles present in the air near communication routes mainly originate from fuel combustion in engines, while coarse particles usually come from non-exhaust sources such as road abrasion, brake

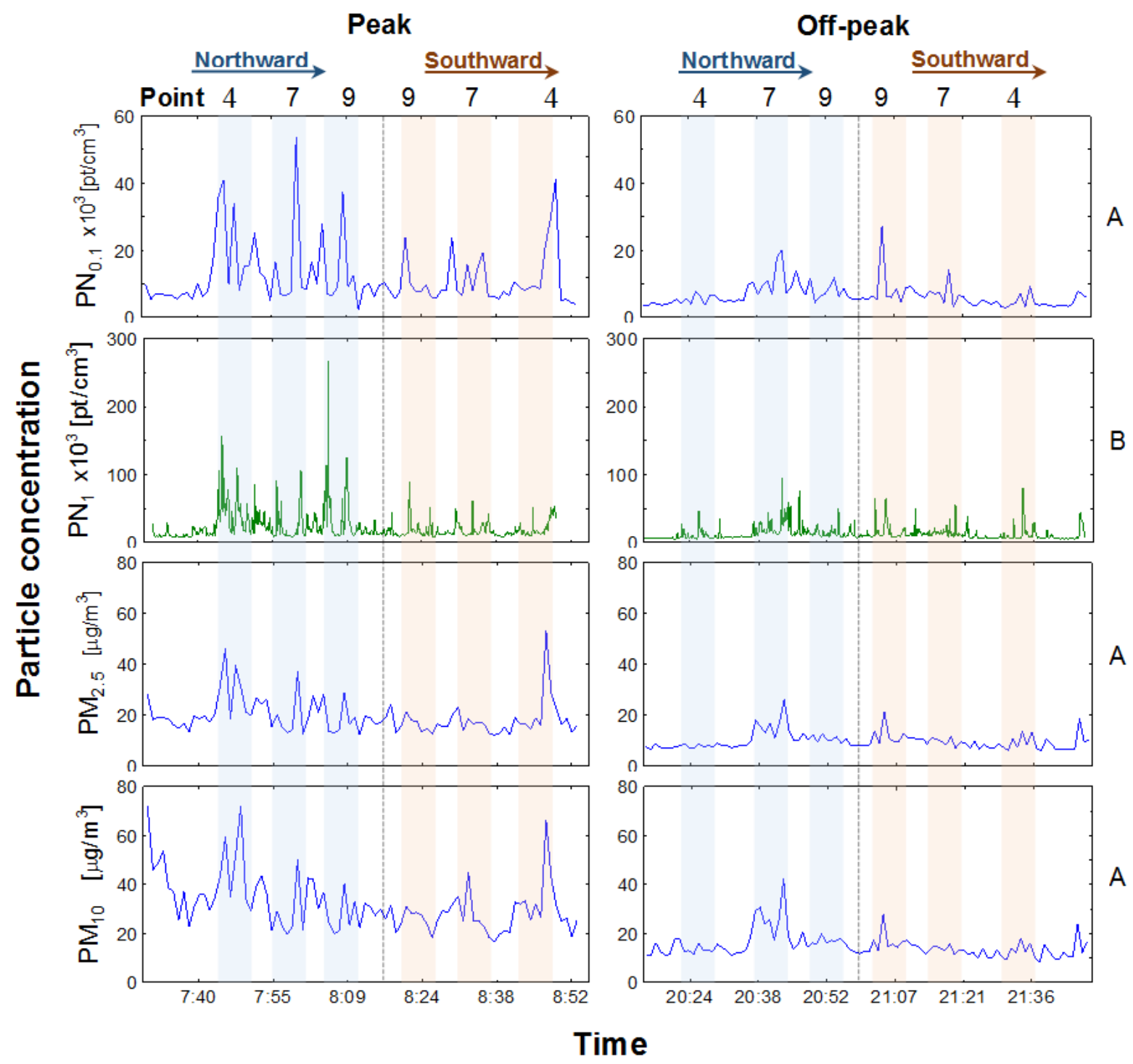

Figure 2. Time series of ultrafine and fine particle number concentrations $\left(\mathrm{PN}_{0.1}, \mathrm{PN}_{1}\right)$ and particle mass concentrations $\left(\mathrm{PM}_{2.5}, \mathrm{PM}_{10}\right)$ in peak and off-peak hours, (4, 7 and 9 - measurement points near 4-way TIs, A - data from Grimm, B - data from P-Trak) 

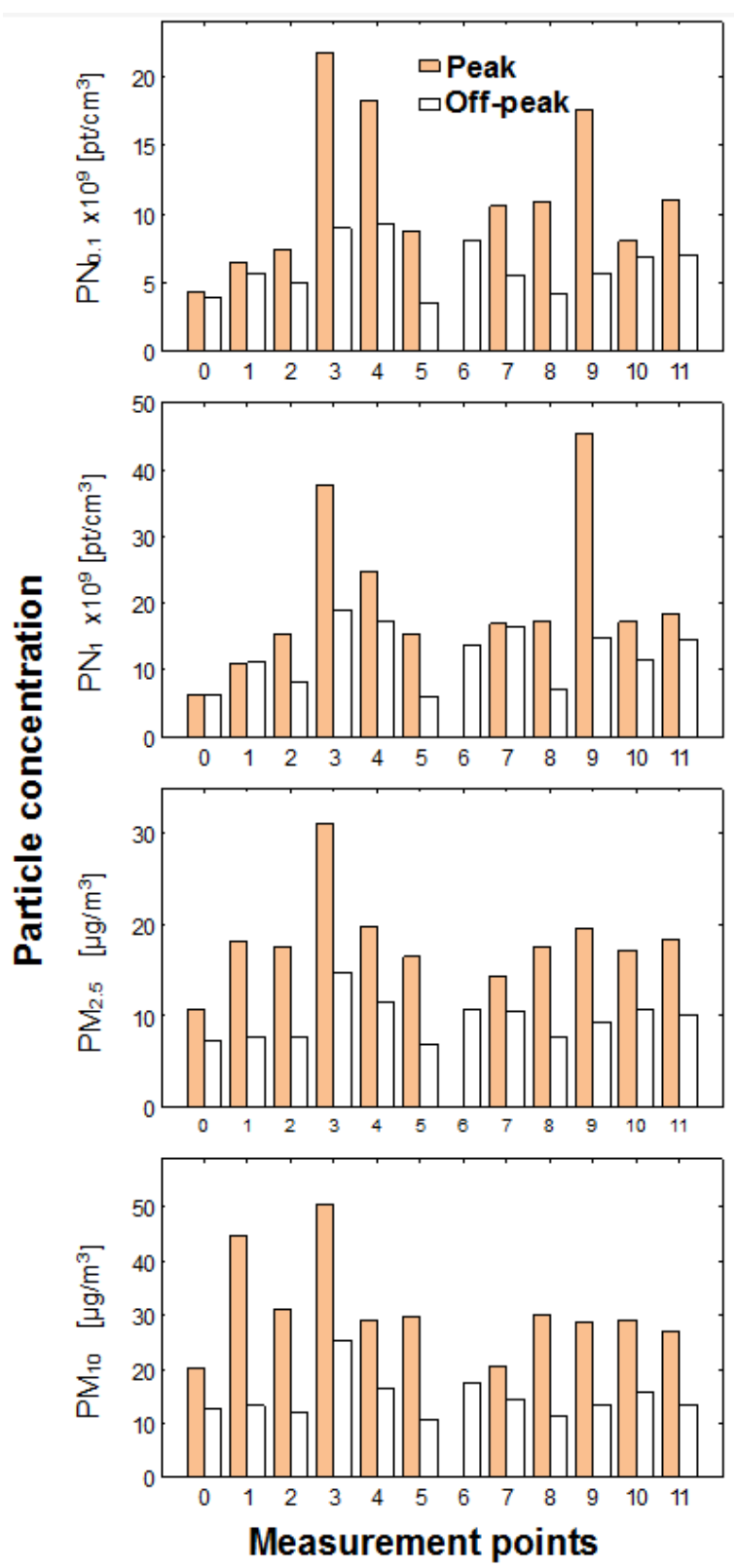

Figure 3. Average values of ultrafine and fine particle number concentrations $\left(\mathrm{PN}_{0.1}, \mathrm{PN}_{1}\right)$ and particle mass concentrations $\left(\mathrm{PM}_{2.5}, \mathrm{PM}_{10}\right)$ in peak and offpeak hours in the individual fixed-site measurement points (based on Grimm and P-Trak measurements) and tire wear [Kumar and Goel 2016, Penkała et al. 2018]. Taking the above into consideration, the comparison of the particle concentrations in the sections of the route with more intense traffic (near 4 way TIs) versus other route sections seems to be of interest.

Table 1 presents basic statistical information on particle number and mass concentrations obtained during on-route and fixed-site measurements in the part of the route with 4-way TIs and for the route sections with less heavy traffic in peak and off-peak traffic hours.

It can be seen in Table 1 that the measured particle concentrations were higher in the peak period. Furthermore, the average particle number concentrations in the route section near 4-way TIs in peak and off-peak hours were about 2 times higher as compared to the part of the route without the 4 -way TIs. The average particle mass concentrations were also about 2 times higher. Similar relations were obtained in the fixed-site measurements.

The exposure for commuters and pedestrians was estimated based on the on-road and fixed-site measurements, respectively. Table 2 presents the estimated doses of the considered particles deposited in the respiratory tract of commuters and pedestrians after spending one hour on the considered route in peak and off-peak traffic times.

Figure 4 provides details on the particle exposure and shows the estimated doses of particles received by commuters and pedestrians after spending an hour in the part of the monitored route with 4-way TIs and route without 4-way TIs in peak and off-peak periods.

The results confirm that the exposure of commuters and pedestrian depends on the given location along the route and the traffic intensity. From the presented data it can be obviously concluded that both commuters as well as pedestrians

Table 1. Descriptive statistics for ultrafine and fine particle number concentrations $\left(\mathrm{PN}_{0.1}, \mathrm{PN}_{1}\right)$ and particle mass concentrations $\left(\mathrm{PM}_{2.5}, \mathrm{PM}_{10}\right)$ for the on-route measurements I - route sections with less heavy traffic and II - route near 4-way TIs in peak (8:00) and off-peak traffic hours (20:00)

\begin{tabular}{|l|l|l|l|l|}
\hline \multirow{2}{*}{ Part of the route } & \multicolumn{5}{|c|}{$\mathrm{PN}_{0.1} \times 10^{3}\left[\mathrm{pt} / \mathrm{cm}^{3}\right]$} & $\mathrm{PN}_{1} \times 10^{3}\left[\mathrm{pt} / \mathrm{cm}^{3}\right]$ & $\mathrm{PM}_{2.5}\left[\mathrm{\mu g} / \mathrm{m}^{3}\right]$ & \multicolumn{1}{|c|}{$\mathrm{PM}_{10}\left[\mu \mathrm{gg} / \mathrm{m}^{3}\right]$} \\
\cline { 2 - 6 } & $9.7(6.5) 8.0 / 2.3-41.1$ & $17.7(11) 14 / 7.8-106$ & $18.4(6.1) 17.2 / 12-46$ & $31.8(10.3) 30 / 18-71$ \\
\hline I & $17.2(13) 12.6 / 5.2-54$ & $32.1(30) 21 / 8.6-267$ & $21.8(9.4) 19.2 / 12-53$ & $32.9(14.1) 29 / 17-72$ \\
\hline II & $5.6(3.3) 4.6 / 2.9-20$ & $10.7(7.1) 8.2 / 5.3-65$ & $8.6(2.5) 8.0 / 5.9-21.5$ & $13.5(3.2) 13 / 8.1-28$ \\
\hline I & $8.3(3.9) 7.0 / 3.2-27$ & $18.2(14.3) 13.2 / 6-94$ & $12.1(4.1) 10.8 / 7.3-26$ & $18.7(7.1) 17 / 11.7-43$ \\
\hline II
\end{tabular}

Arithmetic average (SD)median/min-max/ 
Table 2. Particle exposure of commuters and pedestrians in I - route sections with less heavy traffic and II - route near 4-way TIs in peak and off-peak hours

\begin{tabular}{|cc|c|c|c|c|}
\hline \multirow{2}{*}{\begin{tabular}{c}
\multirow{2}{*}{$\begin{array}{c}\text { Traffic } \\
\text { period }\end{array}$} \\
\cline { 3 - 7 }
\end{tabular}} & $\mathrm{PN}_{0.1} \times 10^{9}[\mathrm{pt} / \mathrm{h}]$ & $\mathrm{PN}_{1} \times 10^{9}[\mathrm{pt} / \mathrm{h}]$ & $\mathrm{PM}_{2.5}[\mu \mathrm{g} / \mathrm{h}]$ & $\mathrm{PM}_{10}[\mu \mathrm{gg} / \mathrm{h}]$ \\
\hline \multirow{2}{*}{ Peak I } & $2.6(1.9) 2.0 / 0.6-10.3$ & $4.9(4.0) 3.5 / 1.7-39.5$ & $2.7(0.9) 2.5 / 1.7-6.5$ & $28.9(9.9) 27.5 / 16.1-64$ \\
& II & $4.3(3.3) 3.2 / 1.4-13.5$ & $8.1(7.6) 5.6 / 2.3-67.2$ & $2.9(1.4) 2.4 / 1.7-7.5$ & $27.1(11.2) 22.3 / 14.6-59$ \\
\hline \multirow{2}{*}{ Off-peak I } & $1.7(1.1) 1.4 / 0.7-6.9$ & $3.2(2.5) 2.4 / 1.4-23.7$ & $1.4(0.5) 1.2 / 0.8-3.7$ & $13.3(5.2) 11.8 / 7.2-37.7$ \\
& II & $1.8(0.6) 1.7 / 0.8-3.5$ & $4.1(3.1) 3.1 / 1.5-20.5$ & $1.5(0.4) 1.4 / 0.9-2.6$ & $13.8(2.8) 14.2 / 9.4-20.9$ \\
\hline & & \multicolumn{5}{|c|}{ Pedestrians } \\
\hline Peak & I & $2.5(1.3) 2.1 / 1.1-5.5$ & $4.4(2.3) 4.1 / 1.6-9.5$ & $2.6(0.8) 2.5 / 1.5-4.4$ & $29.1(8.8) 26.6 / 17.8-44$ \\
& II & $3.9(1.1) 4.4 / 2.7-4.6$ & $7.3(3.7) 6.2 / 4.2-11.4$ & $2.5(0.4) 2.8 / 2.0-2.8$ & $23.0(4.2) 25.3 / 18.2-26$ \\
\hline Off-peak & I & $1.4(0.4) 1.4 / 0.9-2.3$ & $2.8(1.2) 2.8 / 1.5-4.8$ & $1.3(0.4) 1.1 / 1.0-2.1$ & $12.7(3.9) 11.8 / 9.6-22.5$ \\
& II & $1.9(0.5) 2.0 / 1.4-2.3$ & $3.9(0.5) 3.7 / 3.5-4.4$ & $1.5(0.2) 1.5 / 1.3-1.6$ & $14.0(2.0) 14.7 / 11.8-16$ \\
\hline
\end{tabular}

Arithmetic average(SD)median/min-max

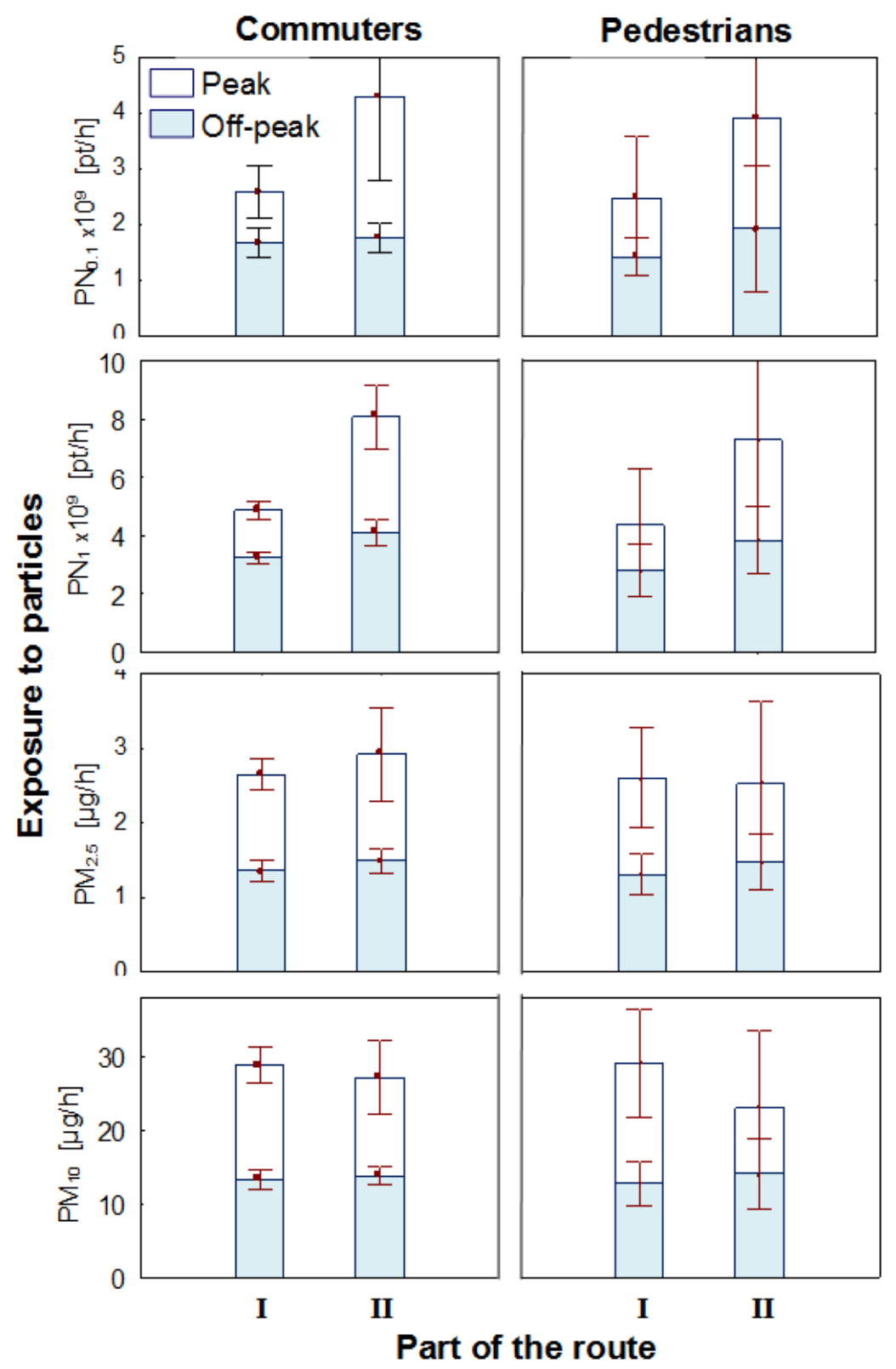

Figure 4. Average particle doses received by commuters and pedestrians during one hour spent in the monitored route in peak and off-peak hours; I - route sections with less heavy traffic and II - route near 4-way TIs (based on Grimm and P-Trak measurements) 
receive greater particle doses during the peak time. Furthermore, both in peak and off-peak traffic times, a greater particle number is inhaled in the considered part of the route with 4-way TIs as compared to the route with less heavy traffic. In turn, in terms of the particle mass, the doses of coarser particles $\left(\mathrm{PM}_{10}\right)$ were higher in the part of the route without 4-way TIs. In the peak period, the average particle doses received by commuters near 4-way TIs equaled $4.3 \pm 3.3 \times 10^{9} \mathrm{pt} / \mathrm{h}$ $\left(\mathrm{PN}_{0.1}\right)$ or $2.9 \pm 1.4 \mu \mathrm{g} / \mathrm{h}\left(\mathrm{PM}_{2.5}\right)$. For pedestrians, such doses amounted to $3.9 \pm 1.1 \times 10^{9} \mathrm{pt} / \mathrm{h}$ or 2.5 $\pm 0.4 \mu \mathrm{g} / \mathrm{h}$. Comparing with the amount estimated during the spring measurements [Połednik et al. 2018], the doses are very similar. Also, considering the particle sizes, they are comparable with the results obtained by Joodatnia et al. [2013]. The slightly higher doses received by commuters are consistent with the findings of Kaur et al. [2005]. It needs to be emphasised at this point that commuters usually drive with closed windows and breathe filtered air.

Summing up, the results of the study show that particle number and mass concentrations observed along the monitored route depend on the traffic intensity, while the resulting exposure of commuters and pedestrians depends on the time of the day and the given route section.

More detailed research should focus on the determination of the dependency between particle concentrations and the exposure in different weather conditions in other seasons in order to devise effective ways to eliminate health risks.

\section{CONCLUSIONS}

The mobile and fixed-site particle number and mass concentration measurements conducted in the summer season along a busy road in Lublin indicated that the results were mainly affected by the traffic intensity. During peak hours the average number concentration of ultrafine particles $\left(\mathrm{PN}_{0.1}\right)$ in the road section near 4-way traffic intersections (TIs) amounted to $17.2 \pm 13 \times 10^{3} \mathrm{pt} /$ $\mathrm{cm}^{3}$ and was about 2 times higher than during off-peak hours. The average mass concentration of particles smaller than $2.5 \mu \mathrm{m}\left(\mathrm{PM}_{25}\right)$ amounted to $21.8 \pm 9.4 \mu \mathrm{g} / \mathrm{m}^{3}$ and was also approximately twice as high than in off-peak hours. Similar relations were found for other measured particle concentrations as well as with respect to the particle exposure. The estimated particle doses inhaled by commuters and pedestrians within an hour near 4-way TIs in peak hours amounted to 4.3 $\pm 3.3 \times 10^{9} \mathrm{pt} / \mathrm{h}\left(\mathrm{PN}_{0.1}\right)$ or $2.9 \pm 1.4 \mu \mathrm{g} / \mathrm{h}\left(\mathrm{PM}_{2.5}\right)$ and $3.9 \pm 1.1 \times 10^{9} \mathrm{pt} / \mathrm{h}\left(\mathrm{PN}_{0.1}\right)$ or $2.5 \pm 0.4 \mu \mathrm{g} / \mathrm{h}\left(\mathrm{PM}_{2.5}\right)$, respectively.

Further research is necessary to examine how particle concentration levels and exposure to particles are affected by the given season and the meteorological conditions.

\section{REFERENCES}

1. EEA, European Environment Agency. Air quality in Europe - 2017 report, http://www.eea.europa. eu/publications/air-quality-in-europe-2017, available 15.12.2018.

2. Goel A., Kumar P. 2015. Characterisation of nanoparticle emissions and exposure at traffic intersections through fast-response mobile and sequential measurements. Atmospheric Environment, 107, 374-390.

3. Joodatnia P., Kumar P., Robins A. 2013. The behaviour of traffic produced nanoparticles in a car cabin and resulting exposure rates. Atmospheric Environment, 65, 40-51.

4. Kaur S., Nieuwenhuijsen M., Colvile R. 2005. Personal exposure of street canyon intersection users to PM2.5, ultrafine particle counts and carbon monoxide in Central London, UK. Atmospheric Environment, 39, 3629-3641.

5. Klejnowski K., Kozielska B., Krasa A., RogulaKozłowska W. 2010. Polycyclic aromatic hydrocarbons in PM1, PM2.5, PM10 and TSP in the Upper Silesian agglomeration, Poland. Archives of Environmental Protection, 36(2), 65-72.

6. Kumar P., Goel A. 2016. Concentration dynamics of coarse and fine particulate matter at and around the signalised traffic intersections. Environmental Science: Processes \& Impacts, 18, 1220-1235.

7. Kumar P., Morawska L., Birmili W., Paasonen P., Hu M., Kulmala M., Harrison R.M., Norford L., Britter R. 2014. Ultrafine particles in cities. Environment International, 66, 1-10.

8. Penkała M., Ogrodnik P., Rogula-Kozłowska W. 2018. Particulate Matter from the Road Surface Abrasion as a Problem of Non-Exhaust Emission Control. Environments, 5(1), 9.

9. Polednik B. 2013. Variations in particle concentrations and indoor air parameters in classrooms in the heating and summer season. Archives of Environmental Protection, 39, 15-28.

10. Połednik B., Piotrowicz A., Pawłowski L., Guz Ł. 2018. Traffic-related particle emissions and exposure on an urban road. Archives of Environmental 
Protection, 2(44), 83-93.

11. Sturm R. 2016. Local lung deposition of ultrafine particles in healthy adults: experimental results and theoretical predictions. Annals of Translational Medicine, 4(21), 420.

12. Suchorab Z., Sobczuk H., Guz Ł., Łagód G. 2017. Gas sensors array as a device to classify mold threat of the buildings, [in:] Pawłowska and Pawłowski (eds.), Environmental Engineering, Taylor and Francis Group.
13. Valavanidis A., Fiotakis K., Vlachogianni T. 2008. Airborne particulate matter and human health: Toxicological assessment and importance of size and composition of particles for oxidative damage and carcinogenic mechanisms. Journal of Environmental Science and Health, 26, 339-362.

14. WHO, World Health Organization, Regional Office for Europe. 2006. Air Quality Guidelines: Global update 2005 - Particulate matter, ozone, nitrogen dioxide and sulfur dioxide, http://www.euro.who. int/en/home, available 15.12.2018. 